\title{
INTERIORIZAÇÃO DO ENSINO SUPERIOR PÚBLICO: EVOLUÇÃO HISTÓRICA DA EDUCAÇÃO EM FREDERICO WESTPHALEN-RS
}

Genesio Mario da Rosa

Fabiana Regina da Silva

\begin{abstract}
Resumo
Apresenta-se neste estudo o processo de evolução da educação em Frederico Westphalen, RS, Brasil, contextualizando-o numa perspectiva histórica, com base em ações sociais, culturais e político-econômicas neste município. Para o estudo foram realizadas pesquisas de campo nos estabelecimentos de ensino da rede pública (municipal, estadual e federal) e particular, envolvendo estabelecimento de ensino básico, fundamental, médio, médio profissionalizante (técnico) e superior. Em termos econômicos, segundo dados apurados, os investimentos realizados ao longo do tempo e especialmente nos últimos dois anos, com a implantação de uma unidade de ensino superior público, devem causar enormes impactos em todas as áreas sociais. Corroborando com a visão de que o investimento em educação é causador do desenvolvimento de uma sociedade mais justa, consciente, digna e solidária, que no caso de Frederico Westphalen, o marco do barril metafórico se transforma em águas de sabedoria.
\end{abstract}

Palavras-chave: Educação, políticas públicas em educação, evolução histórica.

\section{INTERNALIZATION OF PUBLIC HIGHER EDUCATION: HISTORICAL DEVELOPMENT OF EDUCATION IN FREDERICO WESTPHALEN, RS}

\begin{abstract}
This paper introduces the process of evolution of education in Frederico Westphalen, RS, Brazil, through a historical perspective context, based on social, cultural, political, and economical actions in this town. To do so, contextual field research that was used includes both the public education system, that is, federal, state, and municipal, and the private one, ranging from elementary, general and technical secondary, and undergraduate degrees. In economical terms of data available, the investment given since then, and specially these last two years, which has implemented a new public unity of higher teaching, it is expected huge impacts for social areas in a whole. It is supported by that point of view which highlights all educational investment generates development for a society, turning it into a fair, conscious, dignified, and solidary one for living. Frederico Westphalen case here remarks the metaphor of the barrel changing its water into the water of wisdom. Keywords: education; public politics for education; historical evolution.
\end{abstract}




\section{Introdução}

O cenário educacional de Frederico Westphalen-RS, considerado por muitos como um novo pólo educacional, difere em muito do cenário existente no início do século XX, mais especificamente nos anos 20, quando as primeiras carroças, puxadas por juntas de boi ou mulas, conduzidas por carreteiros, comerciantes ou apenas transeuntes, em meio às picadas com destino a localidade de Águas do Mel, hoje cidade de Iraí, faziam da então Barril, parada obrigatória para descanso. Foi esse ponto o marco inicial para a formação da Vila Barril, quando, na época, era território do Município de Palmeira das Missões.

A colonização do local, iniciada principalmente por descendentes de italianos e alemães, tratou logo de iniciar a educação de seus filhos, em rústicas instalações, as quais deram origem, posteriormente, às primeiras salas de aula. É certo, todavia, que a educação não era uma prioridade, uma vez que, segundo Giolo (2002), retirava braços produtivos da lavoura e adicionava gastos ao parco orçamento familiar; corroborando com o autor,esse fato começa a mudar com o início do processo de urbanização, que ocorre com a emancipação do município. No que tange à educação, de todo modo, ao passar das décadas, o ponto de encontro dos carreteiros do início do século atingiu sua emancipação política e administrativa em 1954; Como consequência, em meados de 1960, mais precisamente em 1964, as primeiras escolas de educação secundária foram inauguradas; em 1970, instala-se a Fundação de Educação Superior do Alto Uruguai (FESAU); hoje, dez anos passados do novo milênio, a cidade de Frederico Westphalen afirma-se no cenário nacional como um novo pólo educacional.

É, nessa perspectiva, que este artigo se funda para mostrar, de modo breve, o árduo caminho percorrido pela educação até nossos dias, em um município localizado na região norte do RS, distante $425 \mathrm{~km}$ da capital, Porto Alegre, na intenção de fazer uma leitura de ações realizadas no passado, que se refletem em atitudes hoje observadas. Mais do que nunca, essas ações políticas, econômicas e sociais podem 'ser balizadoras de reflexos futuros de nossas ações no presente.

\section{Desenvolvimento de um Polo Educacional}

\subsection{Breve histórico do Barril}

Frederico Westphalen teve seu início como uma parada de viajantes 
com destino às Águas do Mel (hoje Iraí). Segundo Rizzatti (1996), esse fluxo despertou a atenção da comissão de terras e colonização de Palmeira das Missões, que tratou, como consequência, de abrir uma estrada. $\mathrm{O}$ trabalho teve início em 1917 e, em 1919, a estrada chegou no local denominado de Barril. Esse nome foi dado em virtude da instalação de um barril para o abastecimento de água aos viajantes (Sponchiado, 1989). A partir deste marco, a comunidade começou a se estabelecer e, segundo Ferigollo (2004), já em 1925, eram proferidas as primeiras aulas, ministradas por voluntários na capela erguida em homenagem a Santo Antônio. Os anos se passaram e, em 15 de dezembro de 1954, o governador do Estado do RS, Ernesto Dornelles, promulgou a Lei 2.523, que estabelecia a emancipação do município de Frederico Westphalen (Rizzatti, 1996). De lá para cá, no período 1991-200o, o Índice de Desenvolvimento Humano Municipal (IDH-M) de Frederico Westphalen cresceu 11,80\%, passando de 0,746, em 1991, para o,834, em 2000 (PNUD, 2003), sendo considerado como elevado. Deve-se isso à melhoria sensível da oferta em educação através da rede pública e particular e, principalmente, pelo grande impulso gerado pela instalação, em 1992, do campus da Universidade Regional Integrada do Alto Uruguai e das Missões-URI/FW. O IDH de Frederico Westphalen, segundo o PNUD (2003), indica que a dimensão mais colaboradora para este crescimento, foi a Educação com $39,5 \%$, seguida pela Longevidade, com $35,4 \%$, e pela Renda, com 25,1\%. Neste período, conforme o mesmo relatório, o hiato de desenvolvimento humano (a distância entre o IDH do município e o limite máximo do IDH, ou seja, 1 - IDH) foi reduzido em $34,6 \%$.

A caracterização socioeconômica do município de Frederico Westphalen, segundo dados da FEE (2007), é apresentada na Tabela 1. Também, na mesma tabela, são apresentados os dados socioeconômicos do município de Palmeira das Missões, do qual Frederico Westphalen se emancipou em 1954.

TABELA 1 - Dados socioeconômicos dos municípios de Frederico Westphalen e Palmeira das Missões. FEE (2007) ${ }^{1}$

\begin{tabular}{l|r|r}
\hline Descrição & \multicolumn{1}{c}{ Frederico Westphalen } & \multicolumn{1}{c}{ Palmeira das Missões } \\
\hline Data de criação & $15 / 12 / 1954$ (Lei n $\left.{ }^{\circ} .2523\right)$ & $06 / 05 / 1874$ (Lei $\left.\mathrm{n}^{\circ} .928\right)$ \\
Pop. Total (2006) & 28.226 habitantes & 37.155 habitantes \\
Área (2006) & $265,0 \mathrm{~km}^{2}$ & $1.415,7 \mathrm{~km}^{2}$ \\
Dens. Dem.(2006) & $106,5 \mathrm{hab} / \mathrm{km}^{2}$ & $26,2 \mathrm{hab} / \mathrm{km}^{2}$ \\
Taxa Analf.(2000) & $7,57 \%$ & $12,06 \%$
\end{tabular}


F. R. da Silva; G. M. da Rosa

Expec. de Vida

ao Nascer (2000)

Coef. de Mort. Inf.(2006)

PIBpm(2004) em R\$ mil

PIB percapita (2004)

Exp. Totais (2006)

IDESE (2003)

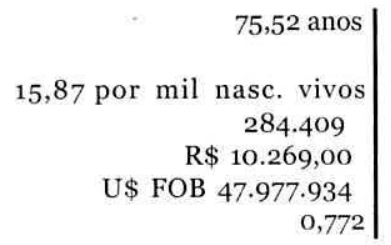

72,06 anos

9,90 por mil nase. vivos

426.531

R\$ $11.832,00$

U\$ FOB 260.000

0,738

Por esses dados, pode-se perceber que, em virtude das ações em educação, iniciadas em 1925, a cidade já apresenta uma população de analfabetos de 4,49 pontos percentuais menor que a cidade de Palmeira das Missões. Já no aspecto social, a melhora na qualidade de vida pode ser percebida pela expectativa de vida que é de 75,52 anos. Comparada com os dados do Instituto Brasileiro de Geografia e Estatística (IBGE), divulgados em 2006, é maior que as médias nacional e da Região Sul, que são 71,9 e 74,5 anos, respectivamente.

\subsection{Da primeira escola à interiorização de cừsos superiores}

O início da educação no "Barril" remonta ao início do século XX quando da instalação, ao redor da hoje "Praça do Barril", das primeiras moradias e casas de comércio. Mais tarde, com o crescente número de jovens que deixavam de estudar por falta de condições financeiras e que tinham de se deslocar aos municípios de Não-Me-Toque, Carazinho, Passo Fundo, Santa Maria, ou até mesmo Porto Alegre, surge a necessidade de iniciar cursos ginasiais (Ferigollo, 2004), que foram a base para a formação das atuais escolas secundaristas e o embrião para a vinda dos cursos superiores.

Pode-se dizer que além da necessidade interna, o aspecto histórico também contribuiu para o processo de acesso ao ensino na cidade, uma vez que esse era privilégio de poucos. Dessa forma, seguindo uma tendência do centro do país, após a Semana da Arte Moderna em 1922 e a criação do Ministério da Educação, pelo então Presidente Getúlio Vargas, em 1932, além do Manifesto dos Pioneiros da Educação, também em 1932, que defendia ideais democráticos e a gratuidade no ensino, criam-se as primeiras escolas no município. Como exemplo disso, pode-se citar o Grupo Escolar da Sede, fundado em 1935, que originou a hoje Escola Estadual Sepé Tiarajú.

No Quadro 1 é apresentada em uma ordem cronológica a instalação de alguns dos estabelecimentos de ensino em Frederico Westphalen. Podese perceber que as primeiras ações realizadas, culminam hoje na existência de quatro instituições de ensino superior e duas de ensino técnico profissionalizante. 
Interiorização do Ensino Superior Público: evolução histórica da educação em Frederico Westphalen-RS Quadro 1 - Cronologia da implantação de alguns estabelecimentos de ensino de Frederico Westphalen de 1925 á 2008.

\begin{tabular}{|l|l|}
\hline Ano & \multicolumn{1}{|c|}{ Entidade de ensino - descricão } \\
\hline 1925 & Aulas na capela no Bairro Barril \\
\hline 1935 & $\begin{array}{l}\text { Grupo Escolar da Sede - Decreto } 5895 \text { - origem da Escola Sepé } \\
\text { Tiaraju }\end{array}$ \\
\hline 1947 & Colégio Nossa Senhora Auxiliadora \\
\hline 1948 & Pré-seminário \\
\hline 1954 & Ginásio Agrícola 7 de Setembro \\
\hline 1957 & Escola de Iniciação Agrícola de Frederico Westphalen \\
\hline 1962 & Curso Ginasial - Origem da Escola Cardeal Roncalli \\
\hline 1962 & Curso Ginasial Colégio Nossa Senhora Auxiliadora \\
\hline 1964 & Escola Técnica do Comércio - 2 ${ }^{0}$ grau \\
\hline 1965 & Escola Técnica José Cañellas \\
\hline 1967 & Curso Normal no Colégio Nossa Senhora Auxiliadora \\
\hline 1967 & Transferência da Escola Agrícola de Frederico Westphalen para o MEC \\
\hline 1969 & $\begin{array}{l}\text { Transferência da Escola Agrícola de Frederico Westphalen para a } \\
\text { UFSM com Colégio Agrícola de Frederico Westphalen }\end{array}$ \\
\hline 1970 & Fundação de Ensino Superior do Alto Uruguai - FESAU \\
\hline 1992 & Universidade Regional Integrada - URI/FW \\
\hline 2003 & Universidade Estadual do RS - UERGS - Campus FW \\
\hline 2004 & Universidade do Norte do Paraná - UNOPAR - Pólo EAD/FW \\
\hline 2005 & Centro de Educação Superior Norte-RS - CESNORS/UFSM - Campus FW \\
\hline
\end{tabular}

No Quadro 2, são apresentados os estabelecimentos que compõe a rede de ensino básico, fundamental e médio e médio profissionalizante, existente em Frederico Westphalen, até 2008. Esta rede é composta por estabelecimentos que tem dependência administrativa distinta, sendo essa em âmbito federal, estadual, municipal e de administração privada.

Quadro 2 - Rede de estabelecimentos de ensino e sua dependência administrativa presentes em Frederico Westphalen até 2008.

\begin{tabular}{|l|l|}
\hline Escola & Dependência administrativa \\
\hline Colégio Agrícola de Frederico Westphalen & Federal \\
\hline E.E.E.F. Affonso Pena & Estadual \\
\hline N. e EJA e CP. Aprendendo a Aprender & Estadual \\
\hline E.E.E.F. Cardeal Roncali & Estadual \\
\hline E.E.E.F. Castelo Branco & Estadual \\
\hline
\end{tabular}




\begin{tabular}{|l|l|} 
E.E.E.F. Cons. Edgar M. de Matos & Estadual \\
\hline E.E.T. José Cañellas & Estadual \\
\hline E.E.E.F. Mons. Vitor Batistella & Estadual \\
\hline E.E.E.F. Nátalia Gadinski & Estadual \\
\hline E.E.E.F. Nossa Senhora de Fátima & Estadual \\
\hline E.E.E.F. Santo Inácio & Estadual \\
\hline E.E.E.B. Sepé Taraiu & Estadual \\
\hline E.E.E.F. Vergílio Cerutti - CIEP & Estadual \\
\hline E.E.E.F. Valdemar Sampaio Barros & Estadual \\
\hline E.M.E.F Alberto Pasqualini & Municipal \\
\hline E.M.E.F Giusto Damo & Municipal \\
\hline E.M.E.E Duque de Caxias & Municipal \\
\hline E.M.E.F. Francisco Cocco & Municipal \\
\hline E.M.E.F. Joaquim Nabuco & Municipal \\
\hline E.M.E.F. Marechal Floriano & Municipal \\
\hline E.M.E.F. Rui Barbosa & Municipal \\
\hline E.M.E.F. Vinte e Um de Abril & Municipal \\
\hline E.M.E.F. Maria Falcon & Municipal \\
\hline E.M.E.F. Irmã Odila Lehnen & Municipal \\
\hline Colégio Nossa Senhora Auxiliadora & Privada \\
\hline E.E.M. Casa Familiar Rural & Privada \\
\hline E.E.B da URI Fred. Westphalen & Privada \\
\hline
\end{tabular}

* O município ainda mantém 6 escolas de educação infantil - pré-escola e creche ** Fonte: Instituto Nacional de Estudos e Pesquisa Educacionais - INEP/MEC2008

Essa nova realidade educacional, além de propiciar aos frederiquenses a chance de uma sequência na educação formal, desde a pré-escola até o ensino superior e pós-graduações, será ponto de convergência e referência na região, permitindo que pessoas de outras cidades e regiões do Estado e do País possam lograr um lugar dentro do sistema educacional brasileiro, nos âmbitos público e privado. Além da esfera educacional, muitas outras áreas deverão ser ampliadas, como setores: imobiliário, comércio e prestação de serviços. Pode-se mencionar ainda que a cidade deve passar por profundas modificações. Como por exemplo, em determinadas épocas, o setor hoteleiro poderá ter grande demanda, pois a cidade passa a fazer parte do circuito das cidades que oferecem um grande número de vagas para vestibular aos cursos superiores, o que acarreta em um grande fluxo 
Interiorização do Ensino Superior Público: evolução histórica da educação em Frederico Westphalen-RS

de candidatos, com a finalidade de prestar esses concursos nas entidades já existentes e nas próximas que, certamente, serão instaladas na cidade.

\subsection{Perspectivas da educação pública de ensino superior em Frederico Westphalen}

Frederico Westphalen possui cinco escolas de ensino médio. Inferese que, na medida em que se difundam e consolidem os estabelecimentos de ensino superior, será fortalecida essa rede de ensino médio, visando atender à nova demanda e a elevar, ainda mais, a qualidade do ensino como um todo, pois, essa injeção de novas pessoas com culturas e formações diferenciadas, sendo disponibilizadas em maior número na sociedade, faz com que o meio educacional se torne mais rico e de certa forma competitivo, exigindo constante aperfeiçoamento. Isso vem de encontro com a Lei de Diretrizes e Bases da Educação Nacional (LDB/96), lei complementar à Constituição Federal, que esclarece em seu artigo 43, entre outros, os seguintes pontos: A educação superior tem por finalidade: 1) estimular a criação cultural e o desenvolvimento do espírito científico e do pensamento reflexivo; 2) formar diplomados nas diferentes áreas de conhecimento, aptos para a inserção em setores profissionais e para a participação no desenvolvimento da sociedade brasileira, e colaborar na sua formação contínua; 3) incentivar o trabalho de pesquisa e investigação científica, visando ao desenvolvimento da ciência e da criação e difusão da cultura, e, desse modo, desenvolver o entendimento do homem no meio em que vive. É nessa lógica que Redin (2006), enfatiza que a educação não pode mais ser vista como gasto público, senão como investimento social e político. Nessa ótica, assume-se que a instalação, por si só, de um campus universitário de uma universidade pública, já é fator que fomentará o crescimento econômico regional em uma visão capitalista, e o desenvolvimento social, em uma visão holística, como objetivo fim.

Expandir o ensino superior sem respeitar as condições mínimas para a formação de bons profissionais (foco na qualidade) e, portanto, cidadãos é um erro grave, histórico e que não pode ser reproduzido, com já foi em décadas passadas. A função das instituições de ensino não é apenas a de instruir. É, sobretudo, a de educar. Nas últimas décadas o que se observou foi o aumento do número de instituições privadas de ensino superior que buscam somente formar profissionais, sem realizar pesquisas ou atividades de extensão, isso sem dúvida representa um atraso no processo de 
formação do conhecimento. Para Santos (2004), a educação brasileira necessita expandir o ensino superior, mas que essas novas instituições tenham como balizadores as atividades de ensino, pesquisa e extensão. Não há dúvida de que a qualidade do "expandir o ensino superior" passa por focar o olhar no setor produtivo e a mente na formação de cidadãos críticos, consciente de seu dever para com o mundo, de seus direitos básicos, da diversidade cultural e multiplicidade de ideias.

Embora sem querer ressaltar o aspecto capitalista da expansão da educação, mas sendo esse um modo imediato de mensurar o impacto da expansão do ensino superior em uma determinada região, obviamente, sem perder de vista o visão holística desse processo, coloca-se a seguir, em evidência a implantação de uma unidade pública de ensino superior em Frederico Westphalen, denominada Centro de Educação Superior NorteRS (CESNORS/UFSM), que teve o início de suas atividades em 16 de outubro de 2006, através da Universidade Federal de Santa Maria, em conjunto com as políticas educacionais que objetivam implantações de cursos superiores fora da sede dos grandes centros urbanos do País. Tendo em vista o exemplo de interiorização de uma universidade pública, gratuita e de qualidade, a Universidade Federal de Santa Maria (UFSM), que promove o ensino superior há cinco décadas, em Santa Maria. Agora, através da iniciativa do atual governo brasileiro em lançar políticas de expansão do ensino superior para o interior do Brasil, especificamente no RS, na região norte, em Frederico Westphalen, inicialmente, a UFSM, com o auxílio da representação de lideranças da região norte do RS, cria três cursos: Engenharia Florestal, Agronomia e Comunicação Social - Jornalismo. Na Tabela 2, apresenta-se o número de alunos, tempo de duração total dos cursos e previsão de alunos no final da fase de implantação, considerando como marco a formatura das primeiras turmas em 2010.

Tabela 2 - Número de alunos, tempo de duração dos cursos e previsão de alunos no final da fase de implantação desses cursos

\begin{tabular}{lccc}
\hline Cursos & No de alunos & Duração & Subtotal de alunos \\
\hline Agronomia & 60 & 5 & 300 \\
Eng. Florestal & 60 & 5 & 300 \\
Comunicação Social & 55 & 4,5 & 220 \\
- Jornalismo & & & 820 \\
\hline Total de alunos & & \\
\hline
\end{tabular}

Fonte: Projeto Político de Criação do CESNORS/UFSM. 2005 
Na região sul do Brasil, o ensino público sempre foi motivo de deslocamento de alunos de todas as regiões do interior para as cidades onde esses eram oferecidos. Era o caso da UFSM, em Santa Maria, a UFRGS, em Porto Alegre, a UFPEL, em Pelotas, a FURG, em Rio Grande; exemplos de referência, assim, podem ser vistas também como a UFSC, em Florianópolis, SC, e a UFPR, em Curitiba, Paraná.

Porém, com a instalação do CESNORS, o fluxo de alunos de outras regiões modifica-se e começa ser sentido desde a sua criação. Na tabela 3 , é apresentado o número de alunos oriundos de outras cidades e regiões do País para Frederico Westphalen.

TABELA 3 - Número de alunos oriundos de outras cidades e regiões do país.

\begin{tabular}{lcl}
\hline Procedência & $\mathrm{N}^{0}$ de alunos & $\%$ \\
\hline Frederico Westphalen & 68 & 19,43 \\
Outras localidades & 282 & 80,57 \\
\hline Total de alunos em março de 2007 & 350 & 100 \\
\hline
\end{tabular}

Fonte: Dados do cadastro de alunos da COPERVES/UFSM

Considerando apenas o percentual de alunos que vem de outras localidades, Tabela 3, e estimando que o custo de manutenção mensal de um aluno com aluguel, alimentação e deslocamento seja de R \$ 550,00 (U\$ $250,34^{2}$ ), o aporte de recurso previsto, apenas com a manutenção dos alunos de outras localidades em Frederico Westphalen, será de aproximadamente 4,67 milhões de reais ao ano, a partir de 2010, Gráfico 1. Infere-se, dessa forma, que além de mudanças no perfil educacional, cultural, entre outros, a cidade passará por um processo de mudança no perfil das demandas e ofertas no setor imobiliário, de comércio e oferta de serviços dos mais diversos para atender a toda essa demanda, antes inexistente.

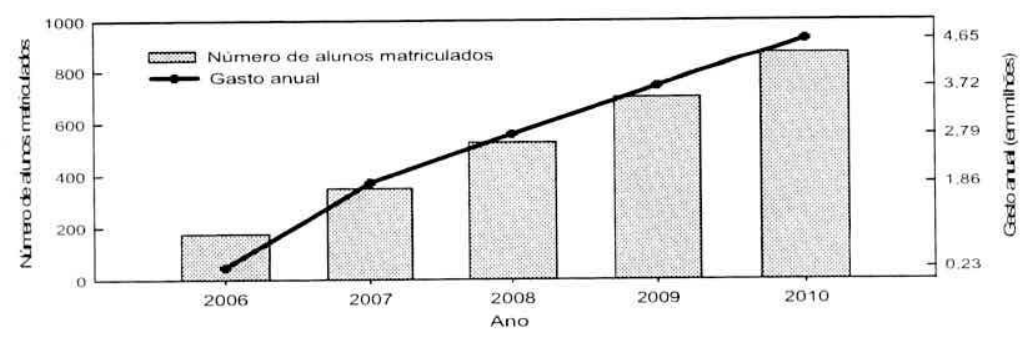

GRÁFICO 1 - Número de alunos matriculados até 2010 e previsão de seus gastos para permanência desses em Frederico Westphalen. 
Outro aspecto importante a ser observado refere-se à folha de pagamento dos servidores, contratados por concurso público para desenvolver atividade de ensino, pesquisa e extensão, tanto como docentes ou de apoio às atividades administrativas. Nesse aspecto, uma comparação importante para compreender o impacto econômico da implantação de uma unidade de ensino superior público na cidade é a relação existente entre o valor recebido, pelo município, do fundo de participação dos municípios (FPM), que em 2007 para Frederico Westphalen foi de R\$ 6.091.697,78 (Tesouro Nacional, 2007), quando comparado com a folha de pagamento que será em 2010, segundo o projeto de implantação do CESNORS/UFSM, campus de Frederico Westphalen, de R $\$ 5.625 .954,40$ (Tabela 4), esse valor equivale a $92,35 \%$ do valor recebido pelo FPM no ano de 2007 . Outro aspecto a ser considerado é a forma de contratação desses profissionais, que terão, por força de lei, dedicação exclusiva às atividades, o que, em última análise, fará com que esses profissionais fixem residência no município e, dessa forma, proporcionem enriquecimento cultural, e desenvolvimento socioeconômico à região. Em uma análise mais crítica, pode-se inferir que o retorno de impostos para a cidade de Frederico Westphalen será dobrada com o advento de uma unidade de ensino superior pública na cidade, uma vez que a folha de pagamento dos servidores é oriunda da arrecadação de impostos.

TABELA 4 - Média de salários e estimativa de folha de pagamento na unidade do CESNORS/UFSM em 2010

\begin{tabular}{l|c|c|c|c|r}
\hline Categoria & $\begin{array}{c}\text { Média } \\
\text { de salário* }\end{array}$ & $\begin{array}{c}\text { Efetivo } \\
\text { em 2008 }\end{array}$ & $\begin{array}{c}\text { Total no ano } \\
\text { de 2008 }\end{array}$ & $\begin{array}{c}\text { Efetivo } \\
\text { em 2010 }\end{array}$ & $\begin{array}{r}\text { Total no ano } \\
\text { de 2010 }\end{array}$ \\
\hline Prof. Adjunto & $\mathrm{R} \$ 6.437,27$ & 23 & $1.973 .602,6$ & 48 & $4.118 .822,8$ \\
Prof. Assistente & $\mathrm{R} \$ 3.937,20$ & 6 & $314.897,3$ & 16 & $839.726,0$ \\
Téc. Admin. & $\mathrm{R} \$ 1.517,21$ & 20 & $404.488,2$ & 33 & $667.405,5$ \\
\hline Total & & & $2.692 .988,1$ & & $5.625 .954,4$ \\
\hline
\end{tabular}

* Valor de referência em outubro de 2008 - Fonte: Coordenadoria de pagamentoCpag/UFSM.

Além da receita imediata na cidade, através das despesas com a manutenção mensal dos alunos vindos de outras localidades para Frederico Westphalen, da folha de pagamento dos servidores, há de se considerar, também, a receita social gerada com a qualificação dos alunos, então gra- 
duados. Segundo o Ministério da Educação (2006), que estima o valor mínimo para um profissional recém formado, para o Rio Grande do Sul, esse valor seria de R\$16.879,46 ao ano. Dessa forma, considerando as primeiras turmas a serem formadas, a partir de 2010, pode-se estimar que, até 2015, quando se completa o primeiro ciclo de formaturas, e considerando que esses formandos ingressem no mercado de trabalho, é prevista uma receita social acumulada de 16,71 milhões de reais (Gráfico 2). Novamente, podemos inferir que o IDH da cidade, que teve acréscimo entre $1991 \mathrm{e}$ 2000 (PNUD, 2003), alavancado pela educação, certamente alcançará índices ainda melhores entre 2006 e 2015.

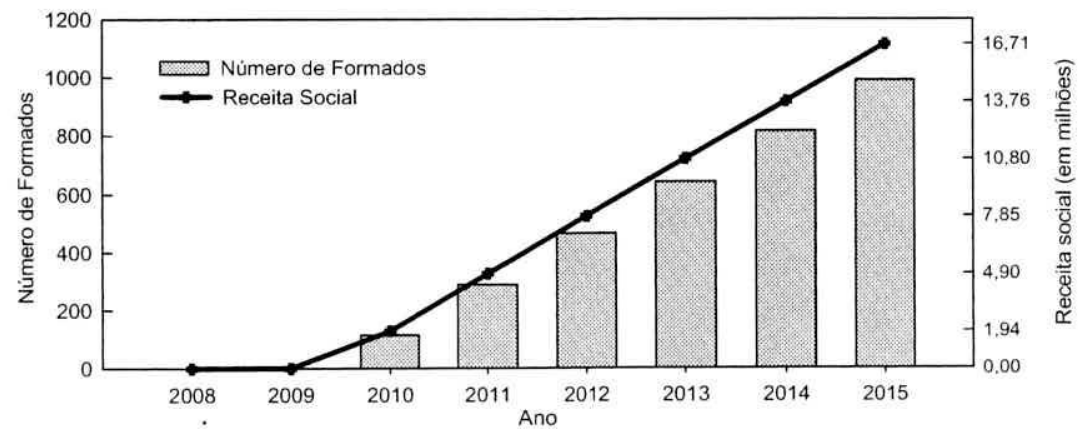

GRÁFICO 2 - Número de formados até 2015 e receita social geradas por esses novos profissionais. Adaptado do Ministério da Educação (2006).

\subsection{Nova perspectiva do ensino superior}

É possível afirmar que, na perspectiva da educação vista aqui, com os dados levantados sobre esse caso de interiorização do ensino superior público, é iniciada uma nova etapa de políticas de universalização da educação pelo Estado, implementadas pelo atual Governo Lula. Não se pode perder de vista, contudo, que também reside nisso o interesse de lideranças políticas e econômicas regionais a incrementar o processo produtivo, com base na tecnologia e na ciência, com vistas à superação da crise da educação e do trabalho, através de uma mudança do perfil estrutural de uma sociedade historicamente dualista e homogeneizadora, conforme indica Frigotto (1998). Acima de tudo, conforme dados históricos pertinentes da região frederiquense, a educação passa por uma transformação de sentido histórico, em que a universidade pública foi inserida. De acordo ainda com Frigotto (1998), essa inserção ajuda na plena cidadania de seus 
indivíduos, desdobrando-se em uma nova matriz de desenvolvimento, que venha a construir em seu contexto histórico, através de novos valores e labores, uma visão crítica da sociedade.

Ainda, as políticas governamentais para expansão do ensino superior, na última década, propiciaram a expansão através de cursos presenciais, como o caso do CESNORS/UFSM, através da iniciativa Federal, e da Universidade Estadual do Rio Grande do Sul - UERGS, na esfera Estadual. Além desses, através de recursos da tecnologia da informação e da comunicação, notadamente a utilização da rede de computadores, com acesso à Internet, novos modelos de ensino também têm sido adotados, para propiciar maior disponibilidade de oferta de cursos superiores. Segundo Peters (2001), o estudo a distância é um método racionalizado de fornecer conhecimento que permite o acesso aos estudos universitários a um grande número de estudantes independentemente de seu lugar de residência e de ocupação. Esse é o caso da Universidade Aberta do Brasil (UAB), que se caracteriza pela utilização de metodologias da educação a distância, e que tem, como prioridade, a formação e capacitação inicial e continuada de professores para a educação básica. Segundo a Coordenação de Aperfeiçoamento de Pessoal do Ensino Superior (CAPES), dentre as atribuições da UAB, encontram-se atividades de articulação das instituições de ensino superior públicas para a oferta de cursos superiores a distância, em polos de apoio presencial, prioritariamente distribuídos em municípios do interior do país.

Para Fontana (2009), esse é um processo educacional que tem como características a democratização do ensino, que necessita a quebra de paradigmas, onde o ensino não seja meramente um produto de reprodução em massa do conhecimento. Atendendo a esse conceito ou não, as políticas públicas para democratização do ensino têm usado essa ferramenta. Assim, essa estratégia tem proporcionado polos de EAD implementados em parceria com prefeituras municipais de difíceis acessos aos grandes centros urbanos. Nesse sentido, esse programa tem tido grande repercussão para atender demandas carentes por cursos de graduação e pós-graduação. Até outubro de 2008, foram registrados pela UAB 32 polos no Rio Grande do Sul, dos quais podem ser destacados os polos das cidades de Seberi, Três Passos e Constantina, que estão todos na Mesorregião do Noroeste do Estado, próximos a cidade de Frederico Westphalen, que, além das ofertas de ensino superior já mencionadas, conta com um Pólo de Ensino a Distância da rede privada, credenciada junto a Universidade do Norte do Paraná - UNOPAR, com sede no Estado do Paraná. 
As críticas a esse modelo educacional são muitas, obviamente não se quer como diz Renner (1995) e Raggat (1993), que citam como aspectos negativos da EAD, a desqualificação dos quadros acadêmicos e técnicos das instituições, além da acentuada desumanização do ensino, com a mediatização e a burocratização das tarefas de ensino e aprendizagem, sejam valorizadas. Nesse sentido, um ponto positivo pode ser ressaltado ao quebrar-se com a EAD, o primeiro grande paradigma da educação no modelo atual, adotado principalmente no ensino superior público, que é a dificuldade de acesso e a democratização do ensino.

Esta ferramenta educacional (EAD) possibilita que o ensino chegue a locais antes desprivilegiados, principalmente devido aos aspectos econômicos das regiões. Este é exatamente o contexto da macrorregião onde está inserida a cidade de Frederico Westphalen, que passa a ser um novo pólo educacional, em virtude das ações realizadas ao longo do tempo, voltadas as políticas educacionais.

\section{Considerações Finais}

Vale lembrar que a educação sempre foi uma condição essencial para uma comunidade crescer e desenvolver seus potenciais culturais, criando oportunidades para o pleno exercício da cidadania de seus indivíduos, como indicado inclusive na própria $\mathrm{LDB} / 96$. Como visto aqui, no norte do RS, o município de Frederico Westphalen, desde que balizou seu desenvolvimento a partir da educação, tem recebido retornos significativos das esferas federal, estadual e de sua própria região. Também, em números recentes, o município tem experimentado o fluxo inverso de uma antiga tradição de sair do interior para estudar nos grandes centros urbanos. Pode-se dizer hoje que Frederico Westphalen e seu entorno recebem alunos para cursar educação superior, advindos de diversos lugares de várias regiões do Brasil. Em termos econômicos, segundo dados apurados, os investimentos devem causar enormes impactos em todas as áreas sociais. Consequentemente, é preciso implementar novas políticas públicas para ampliar toda a rede social de atendimento à comunidade. Tudo isso é fruto de se pensar em educação, seja pública seja privada, seja presencial ou através da modalidade a distância. Como se pode perceber, como a história de Frederico Westphalen tem sublinhado, as iniciativas precisam partir tanto da comunidade quanto das políticas públicas municipais, estaduais e federais, refletindo a necessidade de apoio e articulação para o pleno de- 
senvolvimento de uma sociedade mais justa, consciente, digna e solidária. No caso de Frederico Westphalen, o marco do barril metafórico se transforma em águas de sabedoria e fonte de desenvolvimento social.

\section{Notas:}

1 FEE. Dados Econômicos. Disponível na Internet em <www.fee.tche.br>. Acesso em 25 jul. 07.

2 Valor do dólar 2,197

\section{Referências}

BRASIL. Lei no 9.394, de 20 de dezembro de 1996. Lei de diretrizes e bases da educação, Poder Executivo, Brasília, DF, 23 dez. 1996. Disponível em: <http://www.planalto.gov.br/ccivil_03/LEIS/l9394.html>. Acesso em: 20 set. 2008.

BRASIL. MINISTÉRIO DA EDUCAÇÃO. Expansão as universidades federais o sonho se torna realidade. Período de 2003 a 2006. Brasília, DF, 2006. 103 p.

BRASIL. MINISTÉRIO DA EDUCAÇÃO. Relação de Escolas por Modalidade e Etapa. Instituto Nacional de Estudos e Pesquisa Educacionais, INEP/ MEC. Brasília, DF, 2008.

BRASIL. MINISTÉRIO DA EDUCAÇÃO. Universidade aberta do Brasil. UAB-CAPES. Disponível em <http://uab.capes.gov.br/index.php>. Acesso em: o8 out. 2008.

BRASIL. TESOURO NACIONAL. Brasília, DF, 2008. Disponível em: <http:// www.stn.fazenda.gov.br/ estados_municipios/ municipios.asp >. Acesso em: 30 set. 2008.

CHAUÍ, Marilena. A Universidade Pública sob nova perspectiva. In: CONFERÊNCIA DE ABERTURA DA 26a REUNIÃO ANUAL DA ANPED. 05 de outubro de 2003, Poços de Caldas, MG. Disponível em: <http:// www.anped.org.br/26/marilenachauianped2003.doc >. Acesso em: o3 out. 2008.

IBGE. EXPECTATIVA DE VIDA POR REGIÃO. Rio Grande do Sul: IBGE, 2006.

FEE. Dados Econômicos. Disponível em <www.fee.tche.br >. Acesso em 25 jul. 2007.

FERIGOLLO, W. A. Rostos e rastros no Barril. Frederico Westphalen, RS: Pluma, 2004, 424 p. 
Interiorização do Ensino Superior Público: evolução histórica da educação em Frederico Westphalen-RS FONTANA, Hugo Antônio. Uma filosofia para a Educação a Distância. In anais do II Seminário Nacional de Filosofia e Educação. Universidade Federal de Santa Maria. 2006.

FRIGOTTO, G. (Org.). Educação e crise do trabalho: Perspectivas de final de século. Petrópolis: Vozes, 1998.

MEDEIROS, S. T. V. Ensino Superior: reflexões sobre a universidade dos nossos dias. Revista Ciências Humanas, Frederico Westphalen, v. 7, n. 9, p.1334, dez. 2006.

EDITAL, Gestão universitária. Disponível em http://

www.gestaouniversitaria.com.br/edicoes/30-30/144-a-expansao-do-ensinosuperior-brasileiro.html, acessado em 22 de abril de 2010.

GIOLO, J. Os imigrantes e a educação. In: Raízes italianas do Rio Grande do sul, 1875-1997. Passo fundo: UPF, 2002. 135 p.

LIBÂNEO, João Carlos. Educação Escolar: políticas, estrutura e organização. São Paulo: Cortez, 2005.

PETERS, Otto. Didática da Educação a distância. São Leopoldo: Unisinos, 2001 .

PNUD. Atlas do Desenvolvimento Humano no Brasil. Brasília, DF, 2003.

RAGGATT, P. "Post-Fordism and Distance Education: a Flexible Strategy for Change", in Open Learning, vol. 8, $\mathrm{n}^{\circ} 1,1993$.

REDIN, Euclides; SARDAGNA, H. V.; FRANCO, M. E. W.; CANAN, S. R.; RENNER, W. "Post-Fordist Visions and Tecnological Solutions:

EducationalTechnology and the Labour Process”, in Distance Education, vol.16, $\mathrm{n}^{\circ} 2,1995$.

RIZZATTI, M. E. C. Aspectos significativos da história de Frederico Westphalen. Frederico Westphalen: Marin, 1996. 338 p.

SANTOS, Adriana de Fátima. A expansão do ensino superior brasileiro. In: SPONCHIADO, Breno Antonio. Mons. Vitor Battistella na história de "Barril". Frederico Westphalen: Berthier, 1989. 144 p.

SAVIANI, Dermeval. Política e educação no Brasil. São Paulo:Cortez: Autores Associados, 1987.

UNIVERSIDADE FEDERAL DE SANTA MARIA. Coordenadoria de pagamento. Disponível em http://www.ufsm.br/cpag >. Acesso em: o8 out. 2008.

Universidade federal De SANTA MARIA. Projeto Político de Criação do CESNORS/UFSM. Santa Maria, RS, 2005. 


\section{Genesio Mario da Rosa,}

Doutor em Engenharia Agrícola, Prof Adjunto da Universidade Federal de Santa Maria, Diretor do CESNORS/UFSM.

E-mail para correspondência:

genesiomario@yahoo.com.br

\section{Fabiana Regina da Silva}

Licenciada em História, URI - Universidade Regional Integrada do Alto Uruguai e das Missões - Campus Frederico Westphalen, aluna especial do Programa de Pós-Graduação em Educação-Nível de Mestrado/UFSM e aluna do Pós/ EAD em Gestão Educacional/UFSM

E-mail para correspondência:

fabio4vermelhinho@hotmail.com 